\title{
Nerve Growth Factor Facilitates Cholinergic Neurotransmission between Nucleus Basalis and the Amygdala in Rat: An Electrophysiological Analysis
}

\author{
Hylan C. Moises, ${ }^{1}$ Mark D. Womble, ${ }^{1}$ Mark S. Washburn, ${ }^{1, a}$ and Larry R. Williams ${ }^{2}$ \\ 'Department of Physiology, University of Michigan, Ann Arbor, Michigan 48109-0622 and ${ }^{2}$ Amgen Corporation, Inc., \\ Neurobiology Section, Thousand Oaks, California 91320
}

Treatment of rats in vivo with NGF promotes the survival and enhances the neurotransmitter phenotype of basal forebrain cholinergic neurons. We showed recently (Williams et al., 1993) that NGF-induced stimulations of the cholinergic markers ChAT and high-affinity choline uptake are reflected in an enhanced synthesis and release of $\mathrm{ACh}$ in terminals fields of basal forebrain cholinergic neurons. The objective of the present study was to determine whether such effects translate into an enhancement in neurotransmission between nucleus basalis neurons and postsynaptic target cells, and therefore are likely to be of physiological significance. Changes in cholinergic neurotransmission after NGF were assessed by comparing the ability of cholinergic pathway activation, produced by electrical stimulation of nucleus basalis or the external capsule, to elicit intracellularly recorded muscarinic responses in basolateral amygdaloid (BLA) neurons in ventral forebrain slice preparations from NGF-treated and control Fischer 344 adult rats. Chronic infusion of NGF for 3 weeks $(1.2 \mu \mathrm{g} /$ d, i.c.v.) increased the likelihood of eliciting cholinergic slow depolarizations (slow EPSP) via stimulation of cholinergic pathways in the slice. In addition, the frequency-response curves for generation of the cholinergic slow EPSP by nucleus basalis or external capsule stimulation were shifted approximately twofold to the left and the $E F_{50}$ values significantly reduced in neurons from NGF-treated slices, compared to those in preparations from vehicle-treated or untreated controls. Treatment with NGF also resulted in a leftward shift in the frequency-response curve for cholinergic pathway-induced blockade of the slow afterhyperpolarization, without change in the maximal inhibitory effect. The NGF-induced enhancement in cholinergic synaptic effectiveness was not accompanied by alterations in the resting membrane properties or intrinsic excitability of BLA pyramidal neurons. Nor did treatment with NGF affect their chemosensitivity or responsiveness to direct postsynaptlc applications of the cholinergic agonist carbachol. We con-

\footnotetext{
Received Mar. 22, 1995; revised Aug. 10, 1995; accepted Aug. 15, 1995

This work wats supported NIA Grant AG10667 to H.C.M. L.R.W. was pre viously affiliated with The Upjohn Co., Kalamazoo, MI, during the initia stages of this work.

Correspondence should be addressed to Dr. Hylan C. Moises, Department of Physiology, University of Michigan Medical School, Ann Arbor, MI 48109 0622

Present address: Department of Pharmacology, Fmory Iniversity School of Medicine, Atlanta, GA 30322

Copyright $\bigcirc 1995$ Society for Neuroscience $0270-6474 / 95 / 158131-12 \$ 05.00 / 0$
}

clude from these results that chronic administration of exogenous NGF can facilitate neurotransmission within basal forebrain cholinergic projections in normal adult brain, presumably as a consequence of its ability to stimulate presynaptic mechanisms involved in synthesis and/or release of $\mathrm{ACh}$.

[Key words: NGF, basal forebrain cholinergic neurons, nucleus basalis, basolateral amygdala, slow EPSP, slow afterhyperpolarization]

NGF stimulates the differentiation and growth of cholinergic neurons of the basal forebrain and promotes the expression of the cholinergic neurochemical phenotype (Whittemore and Seiger, 1987; Hefti and Lapchak, 1993). Considerable data derived from rodent models and recent studies in primates also suggest that NGF may be required for maintenance of their functional integrity and survival in adult brain (Thoenen et al., 1987; Araujo et al., 1993a,b; Hefti and Lapchak, 1993). Thus, administration of exogenous NGF has been shown to stimulate the expression of presynaptic cholinergic markers in adult rat and monkey brain, enhancing choline acetyltransferase (ChAT) and acetylcholinesterase (AChE) activities in several forebrain areas and increasing the $V_{\text {max }}$ for sodium-dependent high-affinity choline uptake (IIACU) in septohippocampal and basocortical terminal fields (reviewed in Hefti and Lapchak, 1993; Rylett and Williams, 1994). Similarly, in normal adult rats chronic intraventricular (i.c.v.) administration of $\mathrm{NGF}$ has been reported to increase the expression of NGF receptor and ChAT mRNA and induce hypertrophy of cholinergic neurons within the nucleus basalis, medial septum and diagonal band (Higgins et al., 1989; Fischer et al., 1991). In rats with experimental lesions that model the forebrain cholinergic deficits characteristic of Alzheimer's disease (AD), chronic infusions of NGF i.c.v. were found to prevent degenerative changes and loss of medial septum/diagonal band and nucleus basalis cholinergic neurons following fimbria-fornix transections of the septohippocampal pathway and partial cortical infarction, respectively (Hefti, 1986; Williams et al., 1986; Gage et al., 1988; Hagg et al., 1988; Cuello et al., 1991). Moreover, several groups have reported that behavioral deficits that result from lesions of the fimbria-fornix or nucleus basalis are reversed by administration of NGF (Will and Hefti, 1985; Mandel et al., 1989; Dekker et al., 1992), and in aged, behaviorally impaired rats, i.c.v. infusions of NGF were shown to enhance performance in a spatial memory task and reverse aged-related atrophy of basal forebrain cholinergic neurons ( $\mathrm{Fi}$ scher et al., 1987, 1991). Such findings have led to the proposal 
that administration of NGF might ameliorate deficits in forebrain cholinergic function and thereby play a therapeutic role in the treatment of memory loss and cognitive impairment associated with AD (Hefti and Weiner, 1986; Phelps et al., 1989; Hefti and Lapchak, 1993; Lapchak, 1993).

An important question that remains to consider is whether the stimulation in cholinergic neurochemical activity demonstrated in response to NGF administration is reflected in enhanced synthesis or release of $\mathrm{ACh}$, with a concomitant enhancement in cholinergic neurotransmission in brain. It was first shown in cultured rat septal neurons that incubation with NGF increased depolarization-evoked release of ACh (Takei et al., 1989). Hefti and coworkers (Lapchak et al., 1992; Araujo et al., 1993) subsequently reported in adult rats that chronic i.c.v. infusions of recombinant human NGF rescued septohippocampal cholinergic neurons from degeneration induced by partial fimbrial transections and increased the capacity of surviving hippocampal cholinergic neurons to synthesize, store and release both endogenous and ${ }^{3} \mathrm{H}-\mathrm{ACh}$. Moreover, Rylett et al. (Rylett et al., 1993) recently demonstrated in normal young adult and aged Fischer 344 rats that elevations in ChAT and HACU activity found in frontal cortex, hippocampus and striatum after chronic NGF treatment were accompanied by enhanced ACh synthetic capacity and depolarization-evoked release of both newly synthesized ${ }^{3} \mathrm{H}-\mathrm{ACh}$ and endogenous neurotransmitter, as measured in vitro. While these results are compatible with the view that chronic administration of NGF can facilitate transmitter-related functions in normal and dystrophic cholinergic neurons, it remains to be seen whether these effects translate into an enhancement in cholinergic synaptic activity, and therefore are likely to be of physiological significance. Up to now, it has been difficult to directly examine this issue owing to the lack of a suitable in vitro test system from which the requisite, quantifiable electrophysiological measures of cholinergic neurotransmission can be made.

The amygdaloid complex in rat is known to receive a very dense projection of ACh-containing fibers from the basal forebrain (Woolf and Butcher, 1982; Mesulam et al., 1983; Carlsen et al., 1985; Hellendall et al., 1986), and it is the nuclei contained within the basolateral amygdala (BLA) that provide the major targets of this cholinergic innervation (Carlsen et al., 1985; Carlsen and Heimer, 1986; Hellendall et al., 1986). Immunohistochemical analyses for ChAT indicate that the cholinergic input to the BLA originates largely from neurons of the nucleus basalis and that the cholinergic input terminates predominantly on pyramidal-type neurons (Carlsen et al., 1985; Carlsen and Heimer, 1986; Woolf and Butcher, 1982). We demonstrated by recording intracellularly from BLA pyramidal neurons in rat forebrain slices that the electrophysiological effects produced by cholinomimetics or stimulation of amygdalopetal cholinergic afferents were essentially indistinguishable from those elicited in cerebrocortical or hippocampal pyramidal neurons following muscarinic receptor activation (reviewed in Moises and Womble, 1995). Thus, administration of cholinomimetics or release of endogenous $\mathrm{ACh}$ induced by stimulation of nucleus basalis increased postsynaptic excitability of BLA pyramidal neurons, producing a slow muscarinic depolarization and blockade of the calcium-activated potassium slow afterhyperpolarization (slow AHP) (Washburn and Moises, 1992a; Womble and Moises, $1992,1993)$. The fact that the normal synaptic relationship between cholinergic source neurons and their postsynaptic amygdaloid target cells is maintained in horizontal slice preparations of rat ventral forebrain suggested that the amygdalopetal projec- tion from nucleus basalis to BLA might serve as a model test system for assessing changes in cholinergic neurotransmission in adult brain after treatment in vivo with NGF. In the present study, we compared the ability of cholinergic pathway stimulation to elicit muscarinic responses in BLA pyramidal neurons in slices prepared from NGF- and vehicle-treated Fischer 344 rats to determine whether cholinergic neurotransmission is enhanced after chronic administration of the neurotrophic factor. The sensitivity of pyramidal neurons to bath application of cholinergic agonists was also compared between control and NGF-treated preparations to ascertain the presynaptic versus postsynaptic locus of any changes observed in cholinergic synaptic fidelity after NGF treatment.

\section{Materials and Methods}

Animals and care. Male Fischer 344 rats, 4 months of age, were obtained from the National Institutes on Aging colony at Harlan/SpragueDawley (Indianapolis, IN). Animals were housed in small groups in a temperature $\left(22^{\circ} \mathrm{C}\right)$ controlled room with a daily photoperiod of $12 \mathrm{hr}$ of light between 0600 and $1800 \mathrm{hr}$. Animals had free access to water and were fed ad libitum a standard laboratory diet.

$N G F$ preparation and administration. Three weeks prior to electrophysiological study each animal was implanted with a cannula into the right lateral ventricle using a procedure modified from Williams et al. (Williams et al., 1987). Cannulae were placed under surgical anesthesia induced by intramuscular injection $(4 \mathrm{ml} / \mathrm{kg})$ of a mixture of ketamine (4 mg/ml), xylazine (Rompun, $1.3 \mathrm{mg} / \mathrm{ml}$ ), and acepromzaine $(0.25 \mathrm{mg} /$ ml). Alzet osmotic minipumps, model 2ML4 (Alza Corp., Palo Alto $\mathrm{CA}$ ), were attached to the cannulae and used to deliver sterile reninfree NGF (obtained from Bioproducts for Science, Indianapolis) or vehicle solution for three weeks. The concentration of pure NGF in a stock solution of PBS was determined by molar extinction (1.64 OD280/mg/ml), and aliquots of $1 \mathrm{mg} / \mathrm{ml}$ were stored at $-70^{\circ} \mathrm{C}$ until use. The concentration and biological activity of the NGF solutions were confirmed using the morphological differentiation of PC12 cells in vitro (Buxser et al., 1983). Working solutions were prepared at the time of surgery by dilution in Dulbecco's phosphate-buffered saline containing $0.1 \%$ rat serum albumin (purchased from Sigma Chemical Co., St. Louis), with the diluent also serving as the infusion vehicle. The concentration of NGF in the pump was adjusted for the flow rate of $2.5 \mu \mathrm{l} / \mathrm{hr}$ so that the dose of NGF administered to the rat brain was $1.2 \mu \mathrm{g} / \mathrm{d}$, a dose shown previously to maximally stimulate basal forebrain ChAT activity in axotomized young adult Sprague-Dawley female rats (Williams et al., 1989a). Animals that were infused with vehicle solution with the albumin at $1 \mathrm{mg} / \mathrm{ml}$ added as a nonspecific protein served as controls.

Brain slice preparation. At the end of a 3 week infusion of NGF or vehicle, rats were sacrificed by decapitation and their brains quickly removed and placed in ice-cold oxygenated artificial cerebrospinal fluid (ACSF). The composition of the ACSF (in $\mathrm{mM}$ ) was: $\mathrm{NaCl}, 124 ; \mathrm{KCl}$, 3.5; $\mathrm{CaCl}_{2}, 3.0 ; \mathrm{MgSO}_{4}, 1.5 ; \mathrm{NaH}_{2} \mathrm{PO}_{4}, 1.0 ; \mathrm{NaHCO}_{3}, 26.2$; glucose 11.0. Horizontal slices of ventral forebrain containing the amygdala were cut at a thickness of $500 \mu \mathrm{m}$ using a Vibroslicer (World Precision Instruments). Slices were maintained in a holding chamber at room temperature submerged in ACSF that was continuously bubbled with $95 \% \mathrm{O}_{2}-5 \% \mathrm{CO}_{2}$. Individual slices were transferred to the recording chamber as needed and held submerged between two layers of nylon mesh under continuously flowing ACSF, perfused at a rate of 1.0-1.5 $\mathrm{ml} / \mathrm{min}$ and prewarmed to $32^{\circ} \mathrm{C}$. Slices were allowed to equilibrate at least $1 \mathrm{hr}$ before intracellular recordings were attempted.

Intracellular recording. In the horizontal brain slice preparation used here, the BLA consists of a roughly triangular area that can be identified by its relationship to surrounding anatomical landmarks, being bordered laterally by the external capsule, caudomedially by the lateral ventricle and rostromedially by the stria terminalis. Neurons within this region were impaled with a single microelectrode pulled from $1.2 \mathrm{~mm}$ O.D thin-walled glass capillary tubing. Current-clamp recordings were obtained with microelectrodes filled with $2 \mathrm{M}$ potassium acetate $(\mathrm{pH}=$ 7.0) and having resistances of 90-120 $\mathrm{M} \Omega$ whereas those used for voltage-clamp recording had resistances of 30-100 $\mathrm{M} \Omega$ and were filled with a solution of $2.7 \mathrm{M}$ potassium chloride and $0.4 \mathrm{M}$ potassium acetate. Intracellular discontinuous current current-clamp (DCC) and single- 
clectrode voltage-clamp (SEVC) recordings were made using the $\Lambda \mathrm{x}$ oclamp $2 \mathrm{~A}$ sample and hold amplifier (Axon Instruments, Foster City, CA) with a $30 \%$ duty cycle, as previously described (Womble and Moises, 1992, 1993). The sampling frequency in both modes was approximately $3.0 \mathrm{kHz}$. Amplified signals were displayed on a storage oscilloscope and outputted to a strip chart recorder, while a separate oscilloscope was used to continuously monitor the headstage output to verify that the voltage drop across the electrode had dissipated completely during the interval between current injection ( $30 \%$ of the cycle) and voltage sampling (70\%). Voltage and current signals were also filtered at $300 \mathrm{~Hz}$ and fed to a computer interface (TL-100 interface, Axon Instruments) which digitized (at $0.3 \mathrm{kHz}$ ) the analog waveforms for storage and analysis off-line by a microcomputer-based program (pCLAMP, Axon Instruments). In SEVC mode, gain settings of 3-8 nA/ $\mathrm{mV}$ produced clamp settling times of $<3 \mathrm{msec}$.

Only cells with membrane potentials more negative than $-55 \mathrm{mV}$ and overshooting action potentials were included in this study. Under our recording conditions, the vast majority of BLA neurons were not spontaneously active at the resting membrane potential, but could be made to fire by intracellular injection of depolarizing current through the recording electrode. Prolonged (250-350 $\mathrm{msec}$ ) depolarizing current pulses $(0.5-1.5 \mathrm{nA})$ were passed to cause neurons to discharge a short burst of action potentials, followed by a slow hyperpolarizing afterpotential that emerged upon termination of the depolarizing command, as previously described (Washburn and Moises, 1992a; Womble and Moises, 1993). Input resistance was determined from current voltage plots, constructed from the resultant voltage deflections produced by passage through the recording electrode of an incremental series of $150 \mathrm{msec}$ current pulses $(0.1 \mathrm{nA}$ increments; range, $-0.8 \mathrm{nA}$ to $+1.0 \mathrm{nA}$ ). Meinbrane time constants were calculated for small hyperpolarizing current pulses ( -0.3 to $-0.2 \mathrm{nA}$ ) using a least-squares fit exponential-fitting program (CLAMPFIT, Axon Instruments).

Activation of cholinergic afferents. Cholinergic inputs to BLA neurons were activated by delivering voltage pulses of $0.1 \mathrm{msec}$ duration via a bipolar stimulating electrode placed on the surface of the slice over the nucleus basalis or the external capsule. Changes in the strength/ effectiveness of amygdalopetal cholinergic neurotransmission were assessed by comparing the ability of this electrical stimulation to elicit a slow muscarinic slow excitatory postsynaptic potential (slow EPSP) or inhibit the calcium-activated potassium slow afterhyperpolarization (slow AHP), as described in Washburn and Moises (1992a) in neurons in slices from control and NGF-treated rats. The cholinergic slow EPSP that is recorded in BLA pyramidal neurons results from the muscarinic blockade of both $\mathrm{M}$-current, a voltage-dependent $\mathrm{K}^{+}$conductance, and a second voltage-insensitive $\mathrm{K}^{+}$leak current (Womble and Moises, 1992). For slow EPSP measurements neurons were held $8 \mathrm{mV}$ negative to firing threshold with D.C. current and slow depolarizing responses recorded to a 500 msec tetanic stimulation of nucleus hasalis or the external capsule through which the cholinergic projections travel to reach the BLA (Ichikawa and Hirata, 1986). Manual clamping of the membrane potential $-8 \mathrm{mV}$ relative to spike threshold served to ensure that the test potential $(-66$ to $-62 \mathrm{mV}$ ) from which these responses were elicited was within the mid-range for M-current activation such that a slow EPSP of at least $5 \mathrm{mV}$ ampitude was obtained (see Washburn and Moises, 1992a; Womble and Moises, 1992). For individual neurons, tetanic stimulation of the nucleus basalis or external capsule was first delivered at a constant frequency of $30 \mathrm{~Hz}$ and the stimulus strength adjusted in an incremental manner to establish an optimal range of stimulation intensity for generation of a cholinergic slow EPSP. A series of responses was then evoked by delivering stimuli of a constant intensity at incrementing levels of stimulation frequency $(10-100 \mathrm{~Hz})$ to characterize the stimulus frequency-response relationship. The constancy of stimulation current delivered over the course of the frequencyresponse analysis was routinely monitored by measurement of the voltage drop across a $10 \mathrm{M} \Omega$ precision resistor arranged in parallel with the stimulating electrode. When recording in the presence of eserine (see Results), threshold current intensity for eliciting a slow EPSP to a $500 \mathrm{~ms}, 30 \mathrm{~Hz}$ stimulation of the cholinergic fiber projections averaged $0.45 \pm 0.21 \mathrm{~mA}(0.3-0.75 \mathrm{~mA}$, range for $n=15)$ in slices from NGFtreated rats, which was not significantly different from the mean of 0.53 $\pm 0.28 \mathrm{~mA}(0.4-0.80 \mathrm{~mA}$, range for $n=15)$ for control slices.

The same protocol was used with slight modification to quantitatively evaluate the inhibitory effect of cholinergic pathway stimulation on the slow AHP that followed a current-evoked burst of action potentials. For these experiments, sufficient current was passed through the recording electrode to hold the membrane potential constant at $-60 \mathrm{mV}$ and slow AHPs evoked at $15 \mathrm{sec}$ intervals by passage of an additional $200 \mathrm{msec}$ pulse of depolarizing current. For each neuron, a series of slow AHP responses was collected prior to cholinergic pathway stimulation and following presentation of depolarizing test pulses that were preceded $3-$ $5 \mathrm{sec}$ earlier by a $500 \mathrm{msec}$ tetanic stimulation of nucleus basalis or the external capsule at a frequency of $10-100 \mathrm{~Hz}$. Stimulus intensity was held constant throughout testing in a given neuron and was set to the level found to be optimal for elicitation of the slow cholinergic EPSP. These conditions favored the elicitation of cholinergic synaptic inhibition of the slow AHP, given its much lower threshold for generation compared with that of the slow EPSP (Washburn and Moises, 1992). In the event that cholinergic pathway stimulation produced a slow depolarization of the neuron, the membrane potential was reset to -60 $\mathrm{mV}$ at the time of elicitation of the current-evoked slow AHP to control for any voltage-dependent change in these responses.

Drug application. Drugs were dissolved in ACSF to their final concentration and applied to the slice by switching the bath superfusate from normal ACSF to drug containing medium via a multi-port valve system. In various experiments carbamyl chloride (carbachol), atropine sulfate, eserine or cadmium chloride (all obtained from Sigma Chemical) were added to the bathing medium. Some recordings were obtained in the presence of $1 \mu \mathrm{M}$ tetrodotoxin (TTX, Sigma Chemical) to block action potential-dependent neurotransmitter release, thereby enabling us to confirm the synaptic nature of responses elicited by cholinergic pathway stimulation and to distinguish direct actions of drugs on the neuron under study from possible remote actions.

Data analysis. To construct the frequency-response relationship for elicitation of the cholinergic slow EPSP computerized averages were obtained of depolarizations evoked by three to five stimulation trials at a particular frequency and the peak amplitudes of the averaged responses expressed as absolute changes in millivolts relative to the prestimulation level of membrane potential. The amplitudes of these averaged responses were normalized to the maximal depolarization recorded in a given neuron and plotted as a function of the stimulation frequency to yield a complete frequency-response curve. To quantify the inhibitory effect of cholinergic pathway stimulation on the slow AHP, responses associated with each stimulus frequency were averaged over three trials and the areas of these averaged hyperpolarizing potentials (as measured below) compared against the value obtained for control responses in a given neuron, expressing effects as a \% change ([Control - Test/Control] $\times 100$ ). Cumulative stimulus frequency-response curves were derived by pooling results obtained from populations of neurons from control and NGF-treatment groups, and compared by determining the lowest stimulation frequency which produced a halfmaximal depolarizing response $\left(E F_{50}\right)$ or inhibition of the slow AHP $\left(\mathrm{IF}_{50}\right)$. The results obtained from NGF-treated rats were compared to those from controls using a two-way analysis of variance with repeated measures on one variable (frequency). Post-hoc analysis was done using the Dunnett test to compare the treatment group means to the control group means at each stimulation frequency. A single-blind protocol was followed when recordings were obtained from slices from NGF-treated and vehicle-treated animals with acquisition of data and subsequent analyses being performed without prior knowledge of the treatment regimen.

To quantify the inhibitory action of cholinomimetics on the slow AHP that follows a series of current-evoked action potentials, samples of four to eight digitized waveforms taken before, during drug application and after washout were averaged for each condition. From these averaged records, the area of the slow AHP was then calculated by integrating with respect to time the potential falling below baseline. The lower and upper time limits utilized for the integration of the slow AHP were the time following the current pulse when the slow hyperpolarizing potential first emerged from the decay phase of the preceding medium AHP and the time when the potential returned to the pre-pulse level, respectively. The concentration of drug required to inhibit the control AHP by $50 \%\left(\mathrm{EC}_{50}\right)$ was calculated from the cumulative concentration-response curves generated for NGF-treated and control groups of neuron using linear regression analysis. All data are presented in the text as mean \pm SEM.

\section{Results}

Effects of NGF on resting and active membrane properties The resting membrane properties of BLA pyramidal neurons recorded in slices from NGF-treated rats were not significantly 


$\begin{aligned} & \text { Table 1. Comparison of resting and active membrane properties of basolateral amygdaloid } \\
& \text { pyramidal neurons }\end{aligned}$
\begin{tabular}{lrr} 
Membrane property & \multicolumn{1}{c}{ Controls } & NGF-treated \\
\hline Resting membrane potential (mV) & $-69.5 \pm 0.7(n=45)$ & $-68.5 \pm 0.7(n=40)$ \\
Input resistance (MS) & $39.5 \pm 1.6(n=46)$ & $41.2 \pm 1.9(n=22)$ \\
Time constant (msec) & $15.7 \pm 0.7(n=41)$ & $15.5 \pm 0.9(n=20)$ \\
Action potential duration (msec) & $1.8 \pm 0.1(n=31)$ & $1.8 \pm 0.1(n=22)$ \\
Action potential amplitude (mV) & $93.0 \pm 2.0(n=30)$ & $91.5 \pm 2.7(n=25)$ \\
Slow AHP amplitude (mV) & $6.5 \pm 2.4(n=21)$ & $6.0 \pm 0.5(n=16)$ \\
Slow AHP duration (sec) & $3.6 \pm 0.8(n=21)$ & $3.7 \pm 0.8(n=16)$ \\
\hline All &
\end{tabular}

All data are expressed as mean \pm SEM for the number of neurons indicated.

different from those of control neurons, as shown in Table 1. Data obtained in neurons from vehicle-treated animals $(n=16$, 6 rats) and untreated controls ( $n=29,12$ rats) have been pooled, since no apparent group differences were observed in either their passive or active membrane characteristics. Neurons studied after treatment with NGF ( $n=40,12$ rats) were indistinguishable from controls in regard to their resting membrane potential $(-69.5 \pm 0.7 \mathrm{mV}$ for control, $-68.5 \pm 0.7 \mathrm{mV}$ for treated), input resistance $(39.5 \pm 1.6 \mathrm{M} \Omega$ vs $41.2 \pm 1.9 \mathrm{M} \Omega)$, time constant ( $15.7 \pm 0.7 \mathrm{msec}$ vs $15.5 \pm 0.9 \mathrm{~ms})$, action potential amplitude $(93.0 \pm 2.0 \mathrm{mV}$ vs $91.5 \pm 2.7 \mathrm{mV})$ and spike duration $(1.8 \pm 0.1 \mathrm{mscc}$ vs $1.8 \pm 0.1 \mathrm{mscc})$. The mean threshold for action potential generation also was not significantly different between control $(-59.2 \pm 2.6 \mathrm{mV}, n=30)$ and NGF-treated neurons $(-58.7 \pm 2.3 \mathrm{mV}, n=25)$. In most control and NGFtreated neurons, passage of a prolonged depolarizing current pulse (200-350 msec duration, 0.5-1.5 nA intensity) through the recording electrode evoked a burst of action potentials, followed by a medium and subsequent slow AHP (for example, see Fig. 4 ). The late slow hyperpolarizing potentials recorded in control neurons $(n=21)$ averaged $6.5 \pm 2.4 \mathrm{mV}$ in amplitude, had a mean duration of $3.6 \pm 0.8 \mathrm{sec}$ and were blocked reversibly by bath application of cadmium $(200 \mu \mathrm{M})$. The calcium-dependent slow AHPs recorded in neurons after NGF treatment showed very similar properties (amplitude of $6.0 \pm 0.5 \mathrm{mV}$ and duration of $3.7 \pm 0.8 \mathrm{sec}, n=16$ ).

\section{Responses to cholinergic pathway stimulation}

The effects of activation of cholinergic projections to the BLA were examined in 51 untreated control neurons following stimulation of nucleus basalis $(n=28$ ) or the external capsule ( $n=$ 23). Repetitive stimulation of either site at $30 \mathrm{~Hz}$ for $500 \mathrm{msec}$ (with $0.1 \mathrm{msec}$ stimuli) elicited a series of short-latency fast EPSPs or action potentials followed by a hyperpolarization. We have shown previously that these fast depolarizing responses are noncholinergic in origin and are blocked by glutaminergic antagonists (Washburn and Moises, 1992, and unpublished observations), whereas the hyperpolarizations result from activation

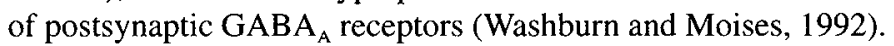
In recordings obtained in normal bathing medium, an atropinesensitive slow EPSP was seen to follow the hyperpolarizing response to nucleus basalis and external capsule stimulation in 8 of $28(29 \%)$ and 12 of $23(52 \%)$ neurons, respectively (Table 2). Bath application of the acetylcholinesterase inhibitor eserine $(2 \mu \mathrm{M})$ increased the likelihood of evoking the slow cholinergic EPSP. Thus, in the presence of eserine a muscarinic slow EPSP was observed in 8 of 9 neurons examined ( $4 / 5$ from nucleus basalis, $4 / 4$ from external capsule) in which tetanic stimulation had failed to evoke slow depolarizing responscs in normal mcdium. These results suggest that the level of acetylcholinesterase activity in the slice is sufficiently high to modulate the efficacy of synaptic transmission within cholinergic projections from nucleus basalis to the BLA. We took advantage of this situation and routinely assessed the ability of cholinergic pathway stimulation to elicit a slow EPSP in control and NGF-treated slices during perfusion of normal bathing medium (containing no eserine) to better reveal a potential ability of NGF administration to enhance cholinergic neurotransmission.

In all neurons the amplitude of the slow EPSP graded directly in relation to both the intensity and the number of stimuli used to activate cholinergic afferents within the slice. In the records shown in Figure $1 A$ from an untreated control neuron, slow EPSPs were recorded with the cell held at a constant depolarized level ( $8 \mathrm{mV}$ negative to threshold at $-66 \mathrm{mV}$ ) while systematically varying the frequency of tetanic stimulation $(0.1 \mathrm{msec}$ pulses at $30 \mathrm{~V}$ intensity) delivered to the nucleus basalis. Whereas single stimuli rarely elicited a slow EPSP, even in the presence of eserine, responses to tetanic stimuli showed marked summation as the stimulation frequency was increased above $10 \mathrm{~Hz}$

Table 2. Occurrence of slow muscarinic depolarizations to cholinergic pathway stimulation

\begin{tabular}{|c|c|c|c|c|c|c|}
\hline \multirow{2}{*}{$\begin{array}{l}\text { Treatment } \\
\text { group }\end{array}$} & \multicolumn{3}{|c|}{$\begin{array}{l}\text { Nucleus basalis stimulation } \\
\text { (cells responding) }\end{array}$} & \multicolumn{3}{|c|}{$\begin{array}{l}\text { External capsule stimulation } \\
\text { (cells responding) }\end{array}$} \\
\hline & Normal medium & In eserine ${ }^{\mu}$ & Total & Normal medium & In eserine $e^{a}$ & Total \\
\hline \multirow{2}{*}{$\begin{array}{r}\text { Untreated } \\
\text { controls }\end{array}$} & 8 of 28 & 4 of 5 & 12 of 28 & 12 of 23 & 4 of 4 & 16 of 23 \\
\hline & $29 \%$ & $80 \%$ & $42.9 \%$ & $52 \%$ & $100 \%$ & $69.6 \%$ \\
\hline \multirow[t]{2}{*}{ NGF-treated } & 12 of 18 & 4 of 4 & 16 of 18 & 12 of 15 & 3 of 3 & 15 of 15 \\
\hline & $66.7 \%$ & $100 \%$ & $83.9 \%$ & $80 \%$ & $100 \%$ & $100 \%$ \\
\hline
\end{tabular}

"Cases shown are those in which a cholinergic slow EPSP was elicited in neurons that failed to respond when testing was carried out in normal bathing medium. 
A

\section{Untreated Control}
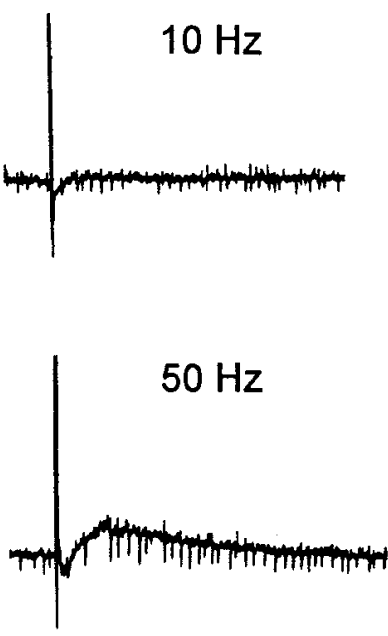

NGF-treated
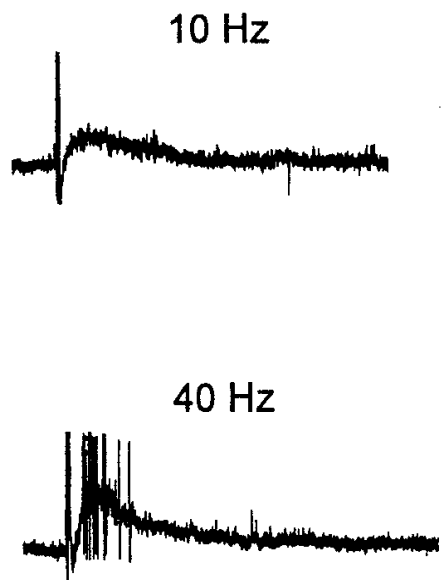
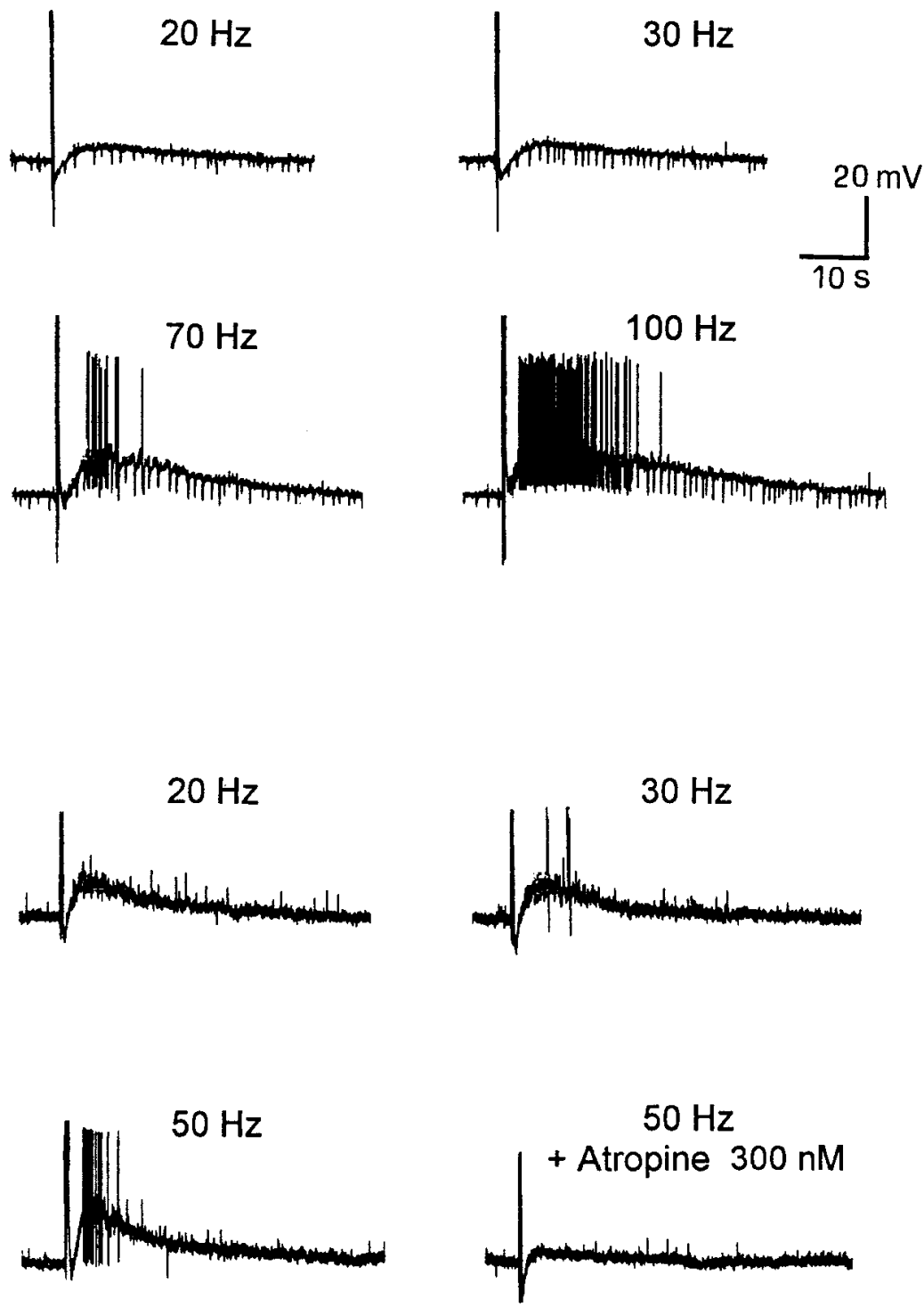

Figure 1. A, Chart records from a control BLA pyramidal neuron illustrate the effect of changing the frequency of tetanic stimulation of nucleus basalis on the cholinergic slow EPSP. Tetanic stimulation consisted of a $500 \mathrm{msec}$ train of pulses of $0.1 \mathrm{msec}$ duration at 30 volts, delivered via a bipolar stimulating electrode placed on the surface of the slice. In this neuron stimulation of nucleus basalis at $10 \mathrm{~Hz}$ defined the threshold for elicitation of the slow EPSP, with graded increases in EPSP amplitude and duration obtained as the stimulation frequency was increased up to 100 Hz. $B$, Chart records from a BLA neuron in an NGF-treated slice illustrate graded increases in amplitude and duration of a cholinergic slow EPSP elicited by $500 \mathrm{msec}$ tetanic stimulation of nucleus basalis at increasing frequencies. In this neuron, the maxinal amplitude of the slow EPSP was produced by cholinergic pathway stimulation at $50 \mathrm{~Hz}$ and the slow synaptic response was abolished by perfusion of atropine 300 nM. Vertical bars at $10 \mathrm{msec}$ in all traces are stimulus artifacts and small deffections in voltage records represent the occurrence of spontaneous synaptic potentials. Responses to cholinergic pathway stimulation were evoked from test potentials of -66 and $-64 \mathrm{mV}$ and resting membrane potentials were $-74 \mathrm{mV}$ and $-73 \mathrm{mV}$, respectively, for the neurons in $A$ and $B$.

and usually reached maximum amplitude at frequencies above $80 \mathrm{~Hz}$. The amplitude of the slow EPSP in many neurons peaked at a level several $\mathrm{mV}$ positive to threshold. However, cholinergic. pathway stimulation at the higher frequencies often resulted in the generation of a short burst of action potentials on the rising phase of the slow depolarizing potential (Fig. 1, record at 70 $\mathrm{Hz}$ ). A $500 \mathrm{msec}$ train of stimuli at $100 \mathrm{~Hz}$ served as the cutoff frequency for evaluation of all stimulus-response relationships, since stimulation at these parameters typically produced prolonged periods of intense discharge which precluded accurate measurement of the peak amplitude of the underlying slow depolarizing potential (see Fig. $1 A$, record at $100 \mathrm{~Hz}$ ).

Figure 2 shows the frequency-response relationships for generation of the cholinergic slow EPSP by stimulation of nucleus 


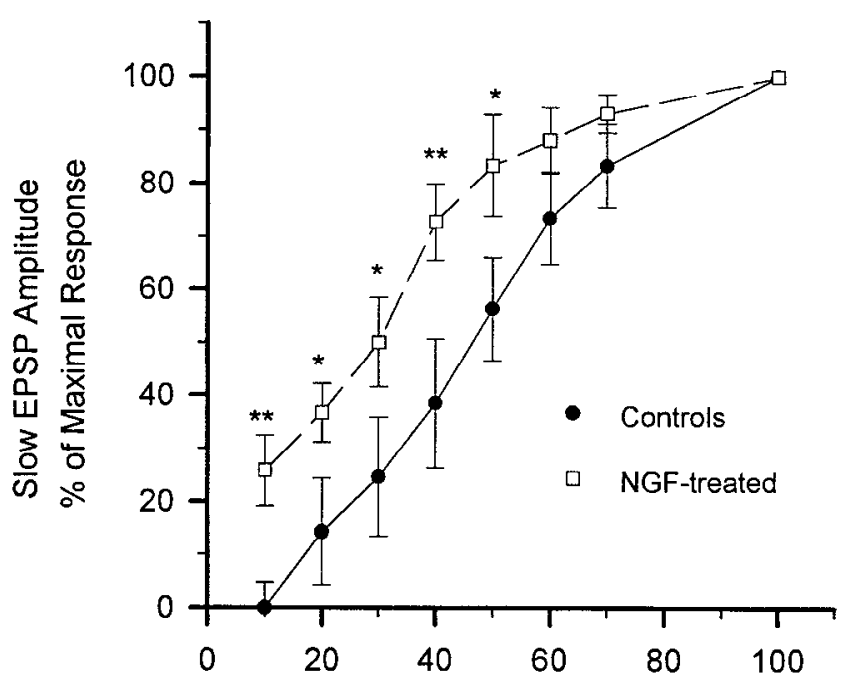

Frequency of NBM Stimulation (Hz)

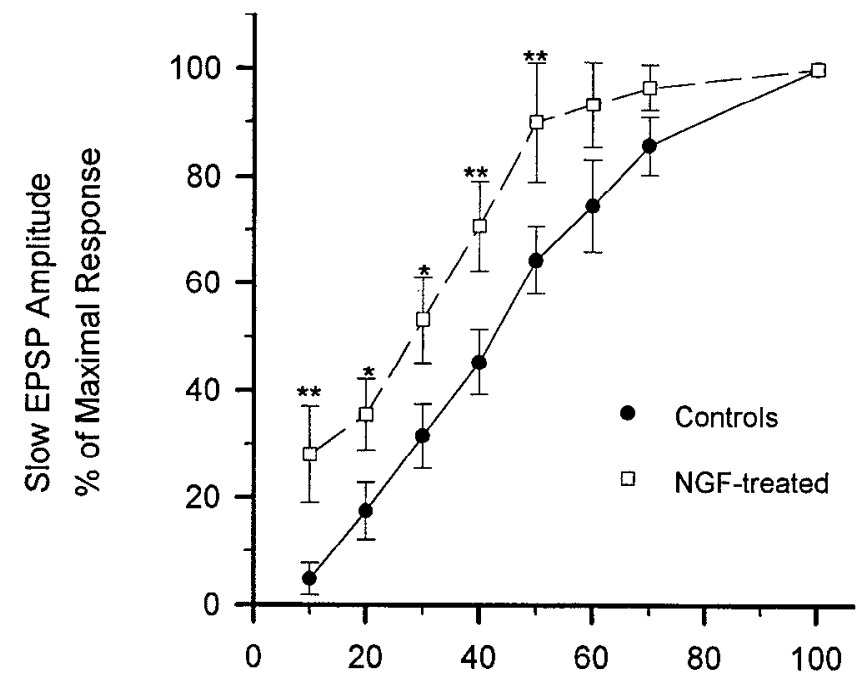

Frequency of EC Stimulation $(\mathrm{Hz})$

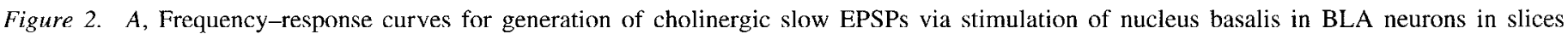
from untreated control (solid circles) and NGF-treated rats (open squares). Chronic treatment of rats with NGF produced a twofold shift to the left in the frequency-response curve for the nucleus basalis-induced slow EPSP, with significant between group effects observed at all test frequencies up to $50 \mathrm{~Hz}$. $B$, Comparison of frequency response curves for slow EPSP generation via external capsule stimulation in untreated control (solid circles) and NGF-treated neurons (open squares) reveals an equivalent potentiative effect of NGF treatment on responses elicited by direct activation of cholinergic afferents to the BLA. All neurons studied in slices taken from NGF-treated animals were located ipsilateral to the site of NGF inlusion. Synibols represent the mean values and enror bars the SEM of determinations in $8-12$ neurons. ${ }^{*}, p<0.05 ; * *, p<0.01$, compared to control.

basalis (Fig. $2 A$ ) and the external capsule (Fig. $2 B$ ) in untreated control (solid circles) and NGF-treated neurons (open squares). A complete stimulus-response curve was generated for each neuron by evoking a series of slow EPSPs using $500 \mathrm{msec}$ trains of $10-100 \mathrm{~Hz}$ stimuli, delivered in an incremental progression of $10 \mathrm{~Hz}$. The averaged responses elicited to three stimulus trials at each stimulation increment were normalized to the peak amplitude of the maximal depolarizing response for that neuron (it bcing designated as $100 \%$ ), and the results for all ncurons of a specified test group were then pooled and plotted as a function of stimulation frequency. Although external capsule stimulation was more efficacious than nucleus basalis stimulation in evoking slow EPSPs in control neurons (Table 2), little difference was noted between the stimulus-response relationships for elicitation of cholinergic depolarizations produced by stimulation of these two sites. Comparison of the control curves generated for untreated neurons revealed that maximal effects were elicited with tetanic stimulation in the range of $90-100 \mathrm{~Hz}$ and yielded $\mathrm{EF}_{50}$ values of $48 \mathrm{~Hz}$ and $42 \mathrm{~Hz}$, respectively, for elicitation of slow cholinergic depolarizations to nucleus basalis and external capsule stimulation.

\section{Effects of NGF treatment on amygdalopetal cholinergic transmission}

Treatment of rats intraventricularly with NGF for 3 weeks increased the likelihood of eliciting slow cholinergic EPSPs either by electrical stimulation of nucleus basalis or via activation of amygdalopetal projections that course within the external capsule. In brain slices that were obtained from the side ipsilateral to the NGF infusion and studied in normal bathing medium, stimulation of the nucleus basalis resulted in the generation of a slow atropine-sensitive EPSP in 12 of $18(66.7 \%)$ neurons, whereas 12 of $15(80 \%)$ neurons responded with a muscarinic slow depolarization to tetanic stimulation of the external capsule (Table 2). In addition, all but two of the 30 neurons examined in these slices responded with a muscarinic slow EPSP when cholinergic pathway stimulation was carried out in the presence of eserine (Table 2). By contrast, a much lower proportion of neurons showed cholinergic responses to nucleus basalis (5 of 14 neurons, $35.7 \%$ in normal ACSF) or external capsule stimulation ( 9 of $16,56.3 \%$ in normal ACSF) in slices prepared from the side of brain contralateral to the site of NGF infusion, mirroring the percentages of responsive neurons found in preparations from untreated controls (Table 2). Nonetheless, administration of eserine $(2 \mu \mathrm{M})$ resulted in the elicitation of cholinergic depolarizations in 6 of 8 neurons that failed to respond to nucleus basalis ( 2 of 4 ) or external capsule stimulation (4 of 4) when recordings were obtained from contralateral side slices during perfusion of control medium. It should be noted that the peak amplitudes of the slow EPSPs, when elicited from test potentials $8 \mathrm{IIV}$ negative to threshold, were not significantly different between control $(10.8 \pm 2.1 \mathrm{mV}$ for nucleus basalis, 11.6 \pm 1.3 for external capsule) and NGF-treated neurons located either ipsilateral $(11.7 \pm 2.1 \mathrm{mV}$ and $12.1 \pm 1.9 \mathrm{mV})$ or contralateral to the site of infusion $(11.4 \pm 2.3 \mathrm{mV}$ and $10.9 \pm 2.5$ $\mathrm{mV}$ ). The slow EPSPs in neurons from NGF-treated rats ( $n=$ 10 examined from the ipsilateral side) also closely resembled those recorded in controls with regard to their voltage dependence $\left(E_{\mathrm{rev}}=-71.5 \pm 2.8 \mathrm{mV}\right.$ compared to $-72.5 \pm 3.1 \mathrm{mV}$ for controls, $n=12$ ) and sensitivity to blockade by atropine (0.3-1 $\mu \mathrm{M}$ being sufficient to eliminate responses to nucelus 


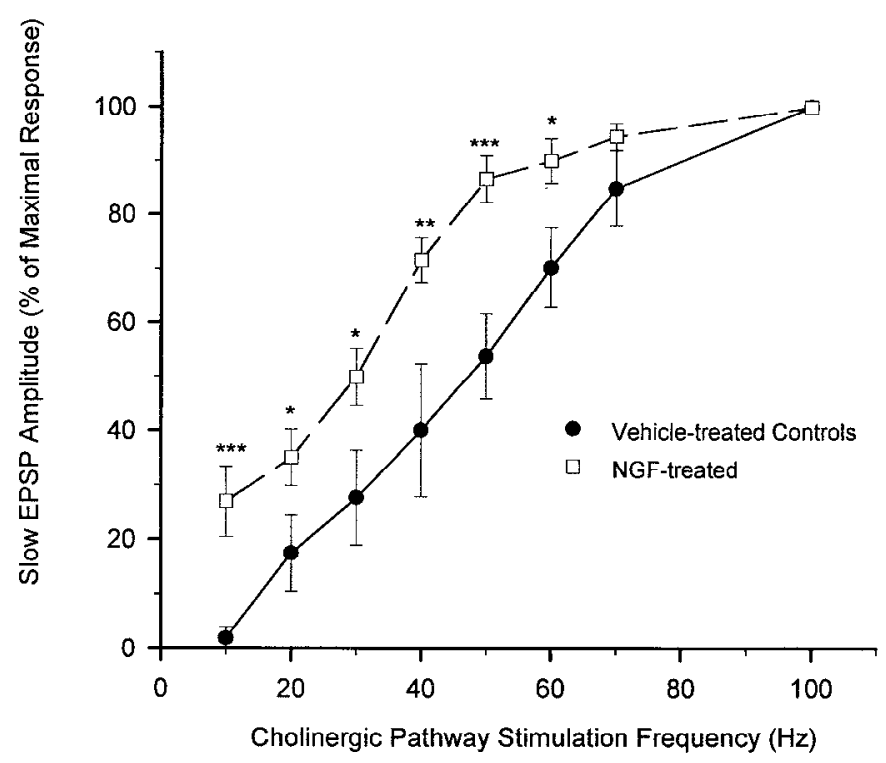

Figure 3. Comparison of frequency-response curves for elicitation of cholinergic slow EPSPs in meurons from NGF-treated slices (open squares) and preparations obtained from vehicle-treated controls (solid circles). The curves shown were constructed by pooling data obtained from trials involving nucleus basalis or external capsule stimulation (see text for details). The $\mathrm{EF}_{50}$ for slow EPSP generation was significantly reduced in slices from NGF-treated animals compared to vehicle-treated controls ( $30 \mathrm{~Hz}$ compared to $48 \mathrm{~Hz}, p<0.01$ ), with significant between group effects of NGF observed at frequencies ranging from 10 to 60 Hz. Symbols represent the mean values and error bars the SEM of determinations in 11 vehicle-treated and 16-24 NGF-treated neurons. $*, p<0.05 ; * *, p<0.01 ; * * *, p<0.005$.

basalis or external capsule stimulation in all neurons tested; see Fig. $1 B$ ).

To quantitatively evaluate this apparent facilitating effect of NGF treatment on cholinergic transmission from the nucleus basalis to the BLA, we compared the stimulus-response relationships for generation of the slow EPSP in neurons from control and NGF-treated slices. Chronic treatment with NGF resulted in a twofold parallel shift to the left in the frequencyresponse curve for the nucleus basalis-induced slow EPSP (Fig. $2 A)$ with a significant group effect $\left(F_{1,19}=14.06, p<0.005\right.$, repeated measures $\Lambda$ NOV $\Lambda$ ). The frequency of nucleus basalis stimulation required to elicit a half-maximal response $\left(\mathrm{EF}_{50}\right)$ was reduced significantly from $47 \pm 5 \mathrm{~Hz}$ in untreated control neurons to $30 \pm 5 \mathrm{~Hz}$ in neurons studied after treatment with NGF ( $p<0.01$, Fig. $2 A$ ). In addition, the amplitudes of the depolarizations elicited by stimulation at frequencies between 10 and $60 \mathrm{~Hz}$ (when normalized to the maximal response for a given neuron) were significantly greater in neurons studied in NGFtreated preparations compared to controls. Treatment of rats with NGF also produced a leftward shift in the frequency-response curve $\left(1.5\right.$-fold at $\left.\mathrm{EF}_{50}, F_{1.23}=8.125, p<0.05\right)$ and significantly reduced the $\mathrm{EF}_{50}$ (from $43 \pm 4 \mathrm{~Hz}$ in untreated controls to 28 $\pm 5 \mathrm{~Hz}, p<0.05$ ) for elicitation of the slow EPSP by external capsule stimulation (Fig. $2 B$ ).

The ability of NGF treatment to enhance amygdalopetal cholinergic transmission was evident as well when comparisons were made between neurons in slices from NGF-treated animals and preparations obtained from vehicle-treated controls (Fig. 3). For these analyses the data derived from nucleus basalis and external stimulation were pooled to obtain sufficient numbers of responsive neurons in control preparations (4/14 to basalis and
$7 / 15$ for capsule stimulation) for construction of frequency-response curves. Visual inspection of the curves depicted in Figure 3 revealed that the $\mathrm{EF}_{50}$ for cvoking cholinergic responses was significantly reduced in neurons from NGF-treated slices compared to those obtained from vehicle-treated controls ( $30 \pm 4$ $\mathrm{Hz}$ versus $48 \pm 7 \mathrm{~Hz}, p<0.01$ ), with significant effects of NGF found at stimulation frequencies ranging from 10 to $60 \mathrm{~Hz}$ (Fig. 3 ). From these data we concluded that the facilitation of cholinergic transmission observed in slices from NGF-treated rats did not arise as a consequence of cannula implantation or brain infusion, but rather most likely reflected a specific effect of NGF administration.

A second electrophysiological endpoint of cholinergic synaptic action that can be elicited in BLA pyramidal neurons by activation of inputs from nucleus basalis is blockade of the slow AHP that follows a burst of action potentials (Washburn and Moises, 1992; Womble and Moises, 1993). These response measurements were obtained concurrently with evaluations of frequency-response relationships for the cholinergic slow EPSP so as to ascertain the reliability of the latter analyses in documenting a facilitation of cholinergic transmission by NGF. With the maximal response to cholinergic pathway stimulation established as $100 \%$ inhibition of the slow AHP for a given neuron, frequency-inhibition curves generated for treatment and control groups could be compared without use of normalized data. The ability of nucleus basalis or external capsule stimulation to inhibit the current-evoked slow AHP was examined in 13 of 20 untreated control and 15 of 24 NGF-treated neurons in which slow cholinergic depolarizations were elicited. As shown by the family of voltage traces in Figure $4 A$ from a control neuron, activation of cholinergic afferents to the BLA via $500 \mathrm{msec}$ tetanic stimulation at either site in the slice produced graded reductions in the current-evoked slow AHP which varied in relation to the stimulus frequency. Stimulation of cholinergic input to the BLA appeared to be equally efficacious in producing suppression of the slow AHP among neurons in control and NGFtreated preparations, yielding averaged maximal inhibitions of $83 \pm 8 \%$ and $90 \pm 6 \%$ of the control response, respectively (Fig. 4B). In contrast, chronic treatment with NGF shifted the frequency-response curve for inhibition of the slow AHP 1.6fold to the left (compared at $\mathrm{EF}_{50}$ level of $26 \pm 7 \mathrm{~Hz}$ versus 41 $\pm 4 \mathrm{~Hz}$ for controls), with significant between group effects of NGF observed at lower stimulation frequencies of $20-40 \mathrm{~Hz}$ ( $p$ $<0.05$, Fig. 4B).

\section{Locus of NGF-induced enhancement in cholinergic transmission}

As noted in the introductory section, the stimulatory effects of NGF on cholinergic neuron function have been shown to result in an augmented release of endogenous ACh elicited by depolarization of cholinergic nerve terminals in brain slice preparations of frontal cortex, hippocampus, or striatum (Rylett et al., 1993). A similar presynaptic mechanism might underlie the enhanced responsiveness of BLA pyramidal neurons to cholinergic pathway stimulation observed here after treatment with NGF. Alternatively, prolonged administration of NGF could have additional effects, possibly independent of those on cholinergic neurons, which serve to increase postsynaptic responsiveness of BLA neurons to cholinergic input from nucleus basalis. To distinguish between these two possibilities we compared the inhibitory effects of bath application of carbachol on the calciumactivated slow AHP that follows a current-evoked burst of action 
A

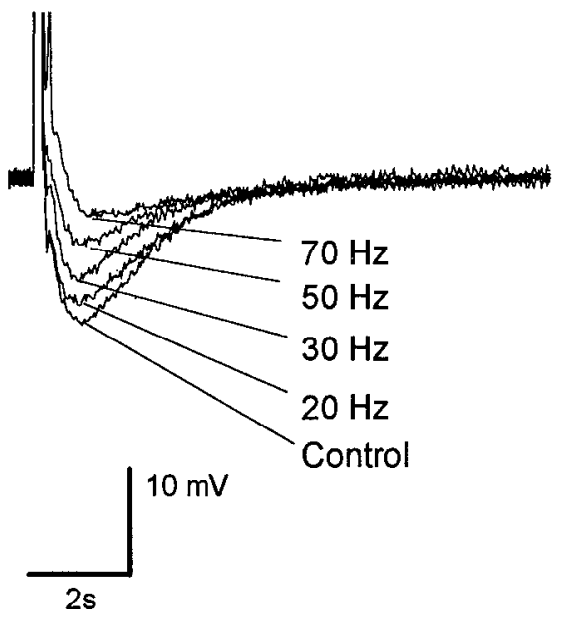

B

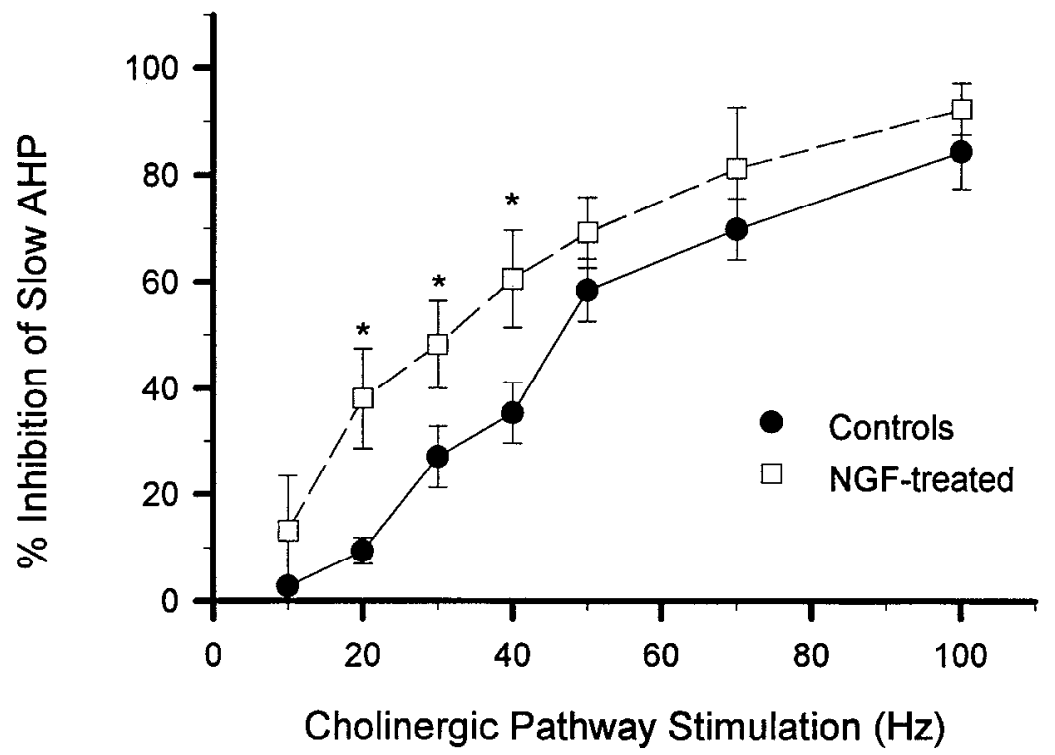

Figure 4. A, Family of voltage traces from an untreated control neuron illustrate graded blockade of the current evoked slow AHP produced by tetanic stimulation of nucleus basalis over a range of frequencies. Each trial consisted of a 500 msec stimulus train of 0.1 msec pulses at $35 \mathrm{~V}$ delivered to nucleus basalis at the indicated frequency. Slow AHP responses were evoked by passage of a $200 \mathrm{msec}$ depolarizing current pulse through the recording electrode. For these measurements, neurons were manually voltage-clamped to $-60 \mathrm{mV}$ to control for possible voltagedependent changes in the slow AHP that would accompany membrane depolarization elicited by cholinergic pathway stimulation. $B$, Frequency response curves comparing the inhibitory effect of cholinergic pathway stimulation within nucleus basalis or the external capsule on the slow AHP in slices from untreated control (solid circles) and NGF-treated rats (open squares). Cholinergic pathway stimulation at 20, 30 , and $40 \mathrm{~Hz}$ produced significantly greater inhibition of the slow AHP in NGF-treated neurons $\left(^{*}, p<0.05\right.$ ), compared to untreated controls. Symbols represent the means and error bars the SEM of determinations in 13 control and 15 NGF-treated neurons.

potentials in pyramidal neurons from control and NGF-treated animals (see Fig. 5A). These experiments were carried out in the presence of TTX $(1 \mu \mathrm{M})$ to ensure that the cffects of the agonist reflected a direct action on the neuron under study. The slow AHPs recorded in NGF-treated neurons $(n=9)$ were essentially indistinguishable from those in controls (untreated, $n$ $=4$; vehicle-treated, $n=5$ ) (Table 1 ), and the responses in all neurons were reduced by carbachol in a reversible and concentration-dependent manner. Treatment of rats with NGF for 3 weeks did not affect the concentration-response curve for carbachol-induced inhibition of the slow AHP (Fig. 5B). Although the maximal inhibitory effect of the agonist was obtained at a slightly lower concentration in NGF-treated neurons $(3 \mu \mathrm{M})$, compared to controls $(10 \mu \mathrm{M})$, there was no significant difference in the $\mathrm{EC}_{50}$ values between the two groups $(0.50 \mu \mathrm{M}$ for controls, $0.47 \mu \mathrm{M}$ for NGF-treated). Similarly, measurements taken under voltage clamp revealed that administration of $3 \mu \mathrm{M}$ carbachol produced comparable (greater than 90\%) suppression of the underlying $I_{\text {ahp }}$ current in control $(n=3)$ and NGF-treated neurons $(n=2)$ (Fig. $5 A$, bottom panel). In current clamp recordings, the carbachol-induced blockade of the slow AHP was sometimes accompanied by a slow cholinergic depolarization, particularly during administration of higher concentrations of agonist. While not systemically examined, the concentration-response relationship for this effect of carbachol did not appear to be different for NGF-treated $(n=3)$ versus control $(n=4)$ neurons, with $300 \mathrm{nM}$ and $10 \mu \mathrm{M}$ of the agonist defining threshold and maxiamlly effective concentrations, respectively, in both groups (data not shown).

\section{Discussion}

The major new finding of this study is that chronic i.c.v. administration of NGF in normal adult rats enhances cholinergic neurotransmission between the nucleus basalis and BLA pyramidal neurons. The enhancement in cholinergic synaptic efficacy that accompanies NGF treatment was manifested here by (1) a marked increase in the probability of eliciting slow muscarinic EPSPs in response to stimulation of nucleus basalis or cholinergic fibers within the external capsule, (2) a twofold leftward shift in the frequency-response relationship for generation of these depolarizing responses, and (3) a significant reduction in the $\mathrm{EF}_{50}$ for blockade of the slow AHP in pyramidal neurons via cholinergic pathway stimulation. Gahwiler and coworkers (Gahwiler et al., 1987) previously reported that administration of NGF to cocultures of septal and hippocampal slices from neonatal rats greatly increased the ingrowth of cholinergic fibers that invaded the hippocampus and that these morphological effects were accompanied by an enhanced synaptic activity monitored by electrophysiological recording from hippocampal pyramidal neurons. In addition, Tuszynski et al. (Tuszynski et al., 1990) were able to restore a cholinergic component of behavioral-dependent hippocampal theta activity following complete interruption of the septo-hippocampal pathway in rats by a combination of intracerebral grafting of fetal hippocampal tissue into the lesion cavity and i.c.v. infusion of NGF. The present data extend these findings by demonstrating that administration of exogenous NGF is capable of modulating the effectiveness of cholinergic transmission not only during development or following damage to axonal pathways but also within intact cholinergic projections of nucleus basalis in normal adult brain. 


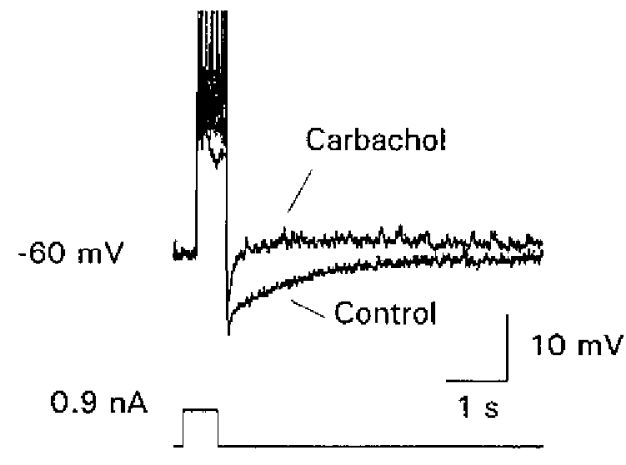

Inhibition of $\mathrm{I}_{\mathrm{AHP}}$

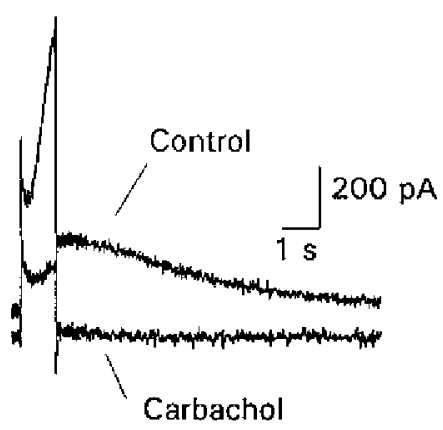

$-40 \mathrm{mV}$

$-60 \mathrm{mV}$

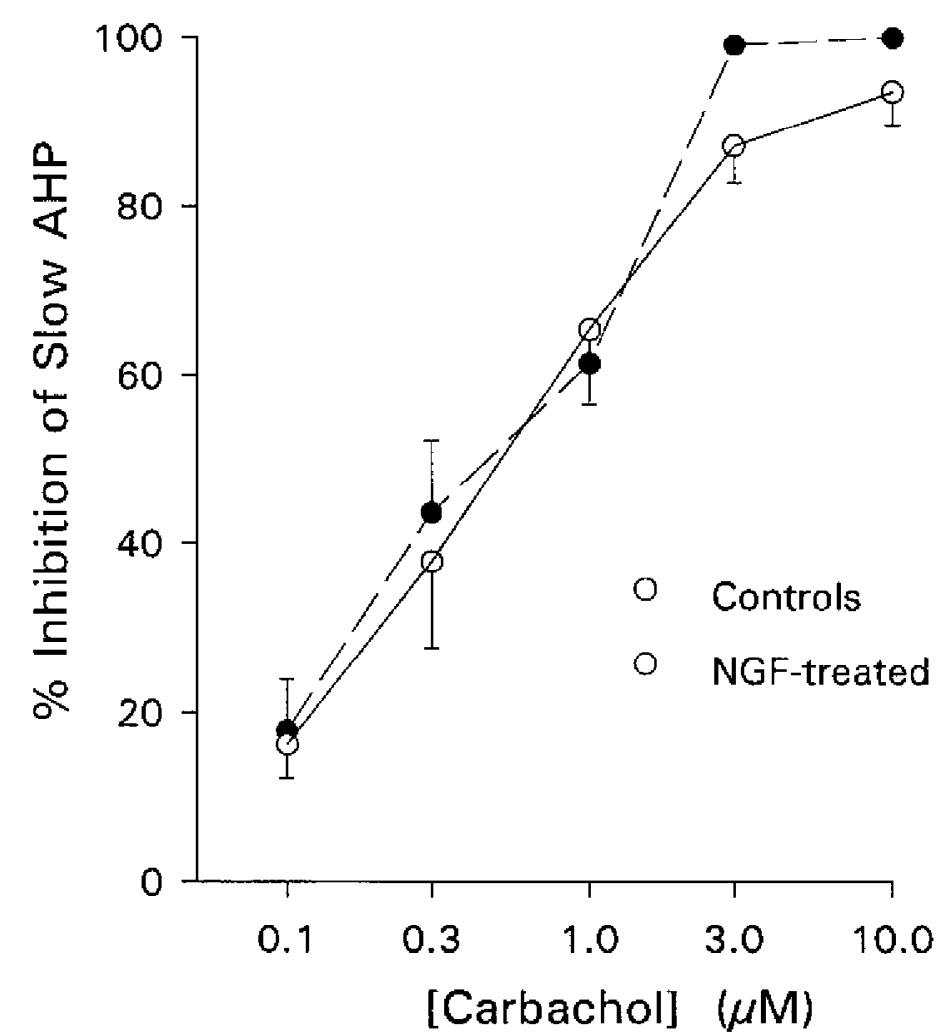

Figure 5. Digitized traces in $A$ illustrate the inhibitory effects of carbachol $(3$ mm) on the slow AHP that foljows a current evoked burst of spikes (upper records) and on the underlying conductance, $I_{\text {ittp }}$, recorded under voltage clamp (lower records). Comparison of voltage traces recorded in the absence and presence of carbachol clearly illustrates blockade of the slow AHP by the cholinergic agonist, but not of the medium AHP that precedes it. $I_{\text {ahp }}$, as shown in lower records, was evoked by a $1 \mathrm{sec}$ depolarizing step to $-40 \mathrm{mV}$ from a holding potential of $-60 \mathrm{mV}$ and measured as the slowly decaying current component that emerged immediately upon termination of the command pulse. $B$, Comparison of concentrationresponse curves for carbachol-induced inhibition of the slow AHP in neurons recorded from control slices (open circles) and in NGF-treated preparations (solid circles). Symbols represent the means and error bars the SEM of determinations from nine control (four untreated and five vehicle-treated) and nine NGF-treated neurons.

Several lines of evidence suggest that the enhancement in cholinergic transmission between nucleus basalis and BLA resulted from a specific trophic action of NGF exerted on the presynaptic cholinergic neurons. First, treatment of rats with NGF for 3 weeks did not alter the resting or active membrane properties of BLA pyramidal ncurons, nor did it affect their intrinsic excitability. Second, the sensitivity and responsiveness of pyramidal neurons to direct application of the muscarinic receptor agonist carbachol were unchanged after NGF treatment. Hence, the enhancement in cholinergic synaptic transmission found after NGF must occur independent of alterations in postsynaptic mechanisms involved in the reception or transduction of the muscarinic signal. In keeping with this are the findings from radioligand experiments that NGF treatment in normal adult rats or those with partial transections of the fimbria/fornix does not alter MI or M2 muscarinic receptor densities in hippocampus (Araujo et al., 1993; Lapchak et al., 1993). Thus, it seems likely that the increased responsiveness to cholinergic pathway stimulation found in forebrain slices from $\mathrm{NGH}$-treated rats reflected changes occurring presynaptically to the neuron under study. Third, such alterations in cholinergic synaptic function can be presumed to reflect a specific effect of NGF, since chronic i.c.v. administration of the vehicle plus albumin as a control protein did not facilitate transmission between nucleus basalis and the BLA. In addition, no significant changes were observed in the effectiveness of cholinergic transmission between nucleus basalis and the BLA in brain slices from NGF-treated animals that were obtained from the side opposite the infusion. Lastly, the facilitation of cholinergic amygdalopetal transmission induced by NGF treatment was most prominently expressed when the effects of cholinergic pathway stimulation were compared in control and NGF-treated slices during superfusion with normal bathing medium. By contrast, no significant difference in responsiveness to cholinergic pathway stimulation was observed between NGF. treated neurons and controls when results from treated animals were compared against data obtained from control slices during blockade of AChE activity with eserine. The latter result supports the hypothesis that the increased efficacy of cholinergic transmission found after treatment with NGF derived at least in part from a facilitation of impulse-dependent release of $\mathrm{ACh}$. 
Recent studies indicate that in addition to its prominent cholinergic input from basal forebrain, the amygdala in rat receives innervation from a second, newly identified population of NGFresponsive neurons in the paraventricular anterior and reuniens nuclei, located within the thalamic medline (Holtzman et al., 1995; Venero et al., 1995). The neurons in these nuclei that demonstrate trkA mRNA expression are noncholinergic, yet they undergo hypertrophy in response to chronic intraventricular infusion of NGF (Venero et al., 1995), as do the ChAT-positive neurons in nucleus basalis (Higgins et al., 1989). Although indirect evidence suggests that the projections from these midline thalamic nuclei may exert an excitatory influence on their amygdaloid targets, we lack sufficient information to predict how NGF-related effects within this neuronal system might influence any of the electrophysiological measurements taken here. Notwithstanding this, the fact that the properties of BLA pyramidal neurons were unaltered after NGF treatment supports the conclusion that altered functioning of this thalamo-amygdaloid projection did not contribute to the observed enhancement in cholinergic neurotransmission between the nucleus basalis and the BLA.

The NGF-induced enhancement of amygdalopetal cholinergic transmission was observed irrespective of whether cholinergic responses in BLA neurons were elicited by electrical stimulation of nucleus basalis or activation of cholinergic fibers within the external capsule. This suggests that the facilitation in cholinergic signaling between nucleus basalis neurons and BLA pyramidal cells resulted from alterations in synaptically related processes, rather than changes affecting cholinergic somatic function. In addition, the observed effects were unlikely to be related to an increased excitability of the cholinergic fibers to electrical stimulation, since the current level that defined threshold stimulation for eliciting cholinergic responses in slices from NGF-treated animals was not significantly different from that for controls. Chronic administration of NGF has been shown to stimulate the expression of cholinergic biosynthetic enzymes in basal forebrain neurons of normal adult and aged rats, increasing the activity of ChAT and producing neuronal hypertrophy within the nucleus basalis and medial septum/diagonal band (Higgins et al., 1989; Williams et al., 1989b), while enhancing the activities of ChAT and HACU in forebrain target areas (Williams and Rylett, 1990; Williams, 1991; Rylett et al., 1993). We reported in frontal cortex and hippocampus of young adult rats that NGF-induced stimulations of ChAT and choline uptake activities were accompanied by an enhanced synaptosomal synthesis of ${ }^{3} \mathrm{H}-\mathrm{ACh}$ (from ${ }^{3} \mathrm{H}$-choline) and increases in basal and depolarization-evoked release of both endogenous and newly synthesized transmitter, measured in vitro from synaptosomal and brain slice preparations (Rylett et al., 1993). In addition, regression analysis revealed that the magnitude of the NGF-induced increase in depolarization-evoked ${ }^{3} \mathrm{H}$-ACh release from cholinergic nerve terminals in cortical or hippocampal slices was highly correlated with the increase in ACh synthesis in both areas (Rylett et al., 1993). A similar relationship might exist for cholinergic projections to the amygdala and account for the NGF-induced enhancement in cholinergic transmission via impulse-dependent release of endogenous $\mathrm{ACh}$ found here. In support of this hypothesis is the demonstration from earlier anatomical work in rat that a small subpopulation of nucleus basalis neurons that project to cortex in rat also provide cholinergic innervation to the BLA (Carlsen et al., 1985). Nevertheless, other studies performed in aged Fishcer 344 rats (Mervis et al., 1991) or in adult animals with unilateral devascularizing cortical lesions have demonstrated that infusion of NGF (Garofalo et al., 1992; Cuello et al., 1993) or implantation of NGF-producing transfected cells (Ernfors et al., 1989) can profoundly effect the cholinergic presynaptic terminal network, eliciting hypertrophy of cortical cholinergic terminals and a remodeling of their synaptic relationships. Conceivably, the net effect of either a proliferation of additional cholinergic synapses or rearrangement of the points of synaptic contact to more strategic loci along the somato-dendritic trec would result in an increased ability of presynaptic cholinergic afferent activity to influence postsynaptic receiving neurons. In future work, it will be necessary to pursue ultrastructural analyses at the EM level in combination with immunostaining for ChAT-positive terminals and varicosities to assess the possibility that the facilitating effect of NGF on cholinergic transmission to the BLA might reflect such a reorganization of the synaptic relationship between cholinergic nerve terminals and their neuronal target cells.

A major contention of this report is that the monosynaptic projection of cholinergic afferents from nucleus basalis to BLA pyramidal neurons provides a useful experimental model to examine the ability of exogenous NGF to promote functional plasticity of forebrain cholinergic projection systems in adult and aged animals. The search for such models has been prompted by an awareness that geriatric cognitive impairment, and Alzheimer's disease in particular, are characterized by dysfunction and loss of basal forebrain cholinergic neurons, and by a growing body of experimental data which suggests that treatment with exogenous NGF might limit the extent of this cholinergic neurodegeneration. Study of the cholinergic projection from nucleus basalis to BLA has relevance from a clinical perspective, given that post-mortem neuropathological examinations of human brain have demonstrated a severe and regionally sclcctive loss of cholinergic innervation of the amygdaloid complex in AD (Sarter and Markowitsch, 1985a; Emre et al., 1993). In addition, experimental studies in rats have shown that disruption of cholinergic amygdalopetal projections from nucleus basalis produces behavioral impairment in a variety of memory tasks (Beninger et al., 1994), as does electrolytic lesioning of the BLA (Sarter and Markowitsch, 1985b).

The postsynaptic effects arising from activation of nucleus basalis cholinergic input to the BLA in rat have now been wellcharacterized by intracellular recording (Washburn and Moises, 1992a; Womble and Moises, 1992, 1993), and the anatomical features of these amygdalopetal projections have been resolved in detail at both the light microscopic and ultrastructural level (Woolf and Butcher, 1982; Mesulam et al., 1983; Carlsen et al., 1985; Hellendall et al., 1986). Moreover, cholinoresponsive neurons within the amygdala appear to be an important source of target-derived NGF. Gall and Isackson (Gall and Isackson, 1989), using in situ hybridization analyses for NGF mRNA, detected moderately dense labeling of neurons throughout the amygdaloid complex in rat. These investigators also found that limbic seizures markedly increased the amygdaloid expression of mRNA for NGF, raising the possibility of a dynamic and activity-dependent regulation of neurotrophic factor production. Nevertheless, uncertainty persists regarding the extent to which target-derived NGF exerts a physiological influence on the specific population of cholinergic neurons that provide innervation to the BLA. Thus, immunohistochemical studies with monoclonal antibodies raised against the low affinity (p75) NGF receptor (NGFr) have revealed only a sparse density of NGFr-positive 
fibers and terminals in rat and primate BLA nucleus (Kordower et al., 1988; Pioro and Cuello, 1990; Heckers and Mesulam, 1994). Recently, Heckers and Mcsulam (Heckers and Mesulam, 1994) showed further in Sprague-Dawley rats that the cholinergic innervation of the BLA remained essentially intact following a complete loss of NGFr-positive neurons in basal forebrain induced by injections of 192 IgG-saporin. The apparent discrepancy between these anatomical observations and the experimental outcome described here might be reconciled based on differences in strains of rodents used, particularly since forebrain cholinergic neurons in the Fischer 344 rat exhibit much greater sensitivity and responsiveness to stimulation by exogenous NGF than do those in Spargue-Dawley rats (Decker, 1987; Williams, 1991). Alternatively, the enhancement in cholinergic transmission between nucleus basalis and BLA that resulted from exogenous NGF administration could reflect an action on cholinergic neurons independent of that normally mediated by the target-derived neurotrophic factor. In this regard, chronic infusion of NGF into adult rat brain has been shown to induce NGFr gene expression in nucleus basalis (Higgins et al., 1989) and result in reexpression in striatal cholinergic neurons of NGF receptors which are lost during postnatal development (Gage et al., 1989). Such a mechanism might act to enhance the responsiveness to exogenously administered NGF, and thereby augment transmitter related functions, among cholinergic amygdalopetal projection neurons, irrespective of their normal NGFr innervation density. In any event, the present results are significant in demonstrating that chronic infusion of NGF can facilitate the transmission of cholinergic signals between nucleus basalis neurons and their postsynaptic target cells in adult brain, yielding an effect that is likely to have physiological relevance for mnemonic processing within the BLA.

\section{References}

Araujo D, Chabot JG, Quirion R (1993a) Potential neurotrophic factors in the mammalian central nervous system. Functional significance in the developing and aging brain. Int Rev Neurobiol 32:141-174.

Araujo DM, Lapchak PA, Hefti F (1993b) Effects of chronic basic fibroblast growth factor administration to rats with partial fimbrial transections on presynaptic cholinergic parameters and muscarinic receptors in the hippocampus: comparison with nerve growth factor. J Neurochem 61:899-910.

Beninger RJ, Kuhnemann S, Ingles JL, Jhamandas K, Boegman RJ (1994) Mnemonic deficits in the double Y-maze are related to the effects of nucleus basalis injections of ibotenic and quisqualic acid on choline acetyltransferase in the rat amygdala. Brain Res Bull 35: $147-152$.

Buxser SE, Watson L, Johnson GL (1983) A comparison of binding proteins and structure of NGF receptor on $\mathrm{PC} 12$ pheochromocytoma and A875 melanoma cells. J Cell Biochem 22:219-233.

Carlsen J, Heimer L (1986) A correlated light and electron microscopic immunocytochemical study of cholinergic terminals and neurons in the rat amygdaloid body with special emphasis on the basolateral amygdaloid nucleus. J Comp Neurol 244:121-136.

Carlsen J, Zaborszky L, Heimer L (1985) Cholinergic projections from the basal forebrain to the basolateral amygdaloid complex: a combined retrograde fluorescent and immunohistochemical study. J Comp Neurol 234:155-167.

Cuello AC, Garofalo L, Maysinger D, Ribeiroda-Silva A (1991) Neurotrophic factor-induced presynaptic morphological and functional changes of the cortical cholinergic input. Boston: Birkhauser.

Cuello AC, Maysinger D, Garofalo L (1993) Trophic factor effects on cholinergic innervation in the cerebral cortex of the adult rat brain. Mol Neurobiol 6:451-461.

Decker MW (1987) The effects of aging on hippocampal and cortical projections of the forebrain cholinergic system. Brain Rcs Rcv 12 : $423-438$.

Dekker AJ, Gage FH, Thal LJ (1992) Delayed treatment with nerve growth factor improves acquisition of a spatial task in rats with lesions of the nucleus basalis magnocellularis: evaluation of the involvement of different neurotransmitter system. Neuroscience 48: $111-119$.

Emre M, Heckers S, Mash DC, Geula C, Mesulam M-M (1993) Cholinergic innervation of the amygdaloid complex in the human brain and its alterations in old age and Alzheimer's disease. J Comp Neurol 336:117-134.

Ernfors P, Ebcndal T, Olson L, Mouton F, Stromberg I, Persson II (1989) A cell line producing recombinant nerve growth factor evokes growth responses in intrinsic grafted central cholinergic neurons. Proc Natl Acad Sci USA 86:4756-4760.

Fischer W, Wictorin K, Bjorklunk A, Williams LR, Varon S, Gage FH (1987) Amelioration of cholinergic neuron atrophy and spatial memory impairment in aged rats by nerve growth factor. Nature 329:6568 .

Fischer W, Rjorklund A, Chen K, Gage HF (1991) NGF improves spatial memory in aged rodents as a function of age. $\mathbf{J}$ Neurosci 11 : 1889-1906.

Gage FH, Armstrong DM, Williams LR, Varon S (1988) Morphological response of axotomized septal neurons to nerve growth factor. J Comp Neurol 269:147-155.

Gage FH, Batchelor P, Chen KS, Chin D, Higgins GA, Koh S, Deputy S, Rosenberg MB, Fischer W, Bjorklund A (1989) NGF receptor reexpression and NGF-mediated cholinergic neuronal hypertrophy in the damaged adult neostriatum. Neuron 2:1177-1184.

Gahwiler BH, Enz A, Hefti F (1987) Nerve growth factor promotes development of the rat septo-hippocampal cholinergic projection in vitro. Neurosci Lett 75:6-10.

Gall CM, Isackson PJ (1989) Limbic seizures increase neuronal production of messenger RNA for nerve growth factor. Science 245:758761.

Garofalo L, Ribeiro-Da-Silva A, Cuello AC (1992) Nerve growth factor-induced synaptogenesis and hypertrophy of cortical cholinergic terminals. Proc Natl Acad Sci USA 89:2639-2643.

Hagg T, Manthorpe M, Vahlsing HL, Varon S (1988) Delayed treatment with nerve growth factor reverse the apparent loss of cholinergic neurons after acute brain damage. Exp Neurol 101:303-312.

Heckers S, Mesulam M-M (1994) Two types of cholinergic projections to the rat amygdala. Neuroscience 60:383-397.

Hefti $F$ (1986) Nerve growth factor promotes survival of septal cholinergic neurons after fimbrial transections. J Neurosci 6:2155-2162.

Hefti F, Lapchak PA (1993) Pharmacology of nerve growth factor in the brain. Adv Pharmacol 24:239-273.

Hefti H, Weiner WJ (1986) Nerve growth factor and Alzheimer's disease. Ann Neurol 20:275-280.

Hellendall RP, Godfrey DA, Ross CD, Armstrong DM, Price JL (1986) The distribution of choline acetyltransferase in the rat amygdaloid complex and adjacent cortical areas, as determined by quantitative micro-assay and immunohistochemistry. J Comp Neurol 249:486498.

Higgins GA, Koh S, Chen KS, Gage FH (1989) NGF induction of NGF receptor gene expression and cholinergic neuronal hypertrophy within the basal forebrain of the adult rat. Neuron 3:247-256.

Holtzman DM, Kilbridge J, Li Y, Cunningham ET, Lenn NJ, Clary DO, Reichardt LF, Mobley WC (1995) TrkA expression in the CNS: Evidence for the existence of several novel NGF-responsive CNS neurons. J Neurosci 15:1567-1576.

Ichikawa T, Hirata Y (1986) Organization of choline acetyltransferasecontaining structures in the forebrain of the rat. J Neurosci 6:281292.

Kordower JH, Bartus RT, Bothwell M, Schatteman G, Gash DM (1988) Nerve growth factor receptor immunoreactivity in the nonhuman primate (Cebus apella): distribution, morphology, and colocalization with cholinergic enzymes. J Comp Neurol 277:465-486.

Lapchak PA (1993) Nerve growth factor pharmacology: application to the treatment of cholinergic neurodegeneration in Alzheimer's disease. Exp Neurol 124:16-20.

Lapchak PA, Jenden DJ, Hefti F (1992) Pharmacological stimulation reveals recombinant human nerve growth factor-induced increases of in vivo hippocampal cholinergic function measured in rats with partial fimbrial transections. Neuroscience 50:847 856 .

Lapchak PA, Araujo DM, Hefti F (1993) Regulation of hippocampal muscarinic receptor function by chronic nerve growth factor treat- 
ment in adult rats with fimbrial transections. Neuroscience 53:379394.

Mandel RJ, Gage FH, Thal LJ (1989) Spatial learning in rats: correlation with cortical choline acetyltransferase and improvement with NGF following NBM damage. Exp Neurol 104:208-217.

Mervis RF, Pope MD, Lewis R, Dvorak RM, Williams LR (1991) Exogenous nerve growth factor reverses age-related structural changes in neocortical neurons in the aging rat: a quantitative golgi study. Ann New York Acad Sci 640:95-101.

Mesulam MM, Mufson EJ, Wainer BH, Levey AI (1983) Central cholinergic pathways in the rat: an overview based on an alternative nomenclature (Ch1-Ch6). Neuroscience 10:1185-1201.

Moises HC, Womble MD (1995) Acetylcholine-operated ionic conductances in central neurons. In: CNS neurotransmitters and neuroInodulators. Acetylcholine (Stone TW, ed), pp 129-144. Boca Raton: CRC.

Phelps CH, Gage FH, Growdon JH, Hefti F, Harbaugh R, Johnston MV, Khachaturian ZS, Mobley WC, Price DL, Raskind M, Simpkins J, Thal LJ, Woodcock J (1989) Potential use of nerve growth factor to treatment Alzheimer's disease. Neurobiol Aging 10:205-207.

Pioro EP, Cuello AC (1990) Distribution of nerve growth factor receptor-like immunoreactivity in the adult rat central nervous system. Effect of colchicine and correlation with the cholinergic system. I. Forebrain. Neuroscience 34:57-87.

Rylett RJ, Williams LR (1994) Role of neurotrophins in cholinergicneurone function in the adult and aged CNS. Trends Neurosci 17: 486-490.

Rylett RJ, Goddard S, Schmidt BM, Williams LR (1993) Acetylcholine synthesis and release following continuous intracerebral administration of NGF in adult and aged Fischer-344 rats. J Neurosci 13:39563963.

Sarter M, Markowitsch HJ (1985) Involvement of the amygdala in learning and memory: a critical review, with emphasis on anatomical relations. Behav Neurosci 99:342-380.

Sarter M, Markowitsch HJ (1985) The amygdala's role in human mnemonic processing. Cortex 21:7-24.

Takei N, Tsukui H. Hatanaka H (1989) Intracellular storage and evoked release of acetylcholine from postnatal rat basal forebrain cholinergic neurons in culture with nerve growth factor. J Neurochem 53:14051410.

Thoenen H, Bandtlow C, Heumann R (1987) The physiological function of nerve growth factor in the central nervous system: comparison with the periphery. Rev Physiol Biochem Pharmacol 109:145-178.

Tuszynski MH, Buzsaki G, Gage FH (199.0) Nerve growth factor infusions combined with fetal hippocampal grafts enhance reconstruction of the lesioned septohippocampal projection. Neuroscience 36: $33-44$.
Ventero JL, Hefti F, Beck D (1995) Retrograde transport of nerve growth factor from hippocampus and amygdala to trkA messenger RNA expressing neurons in paraventricular and reuniens nuclei of the thalamus. Neuroscience $64: 855-860$.

Washburn MS, Moises HC (1992a) Inhibitory responses of rat basolateral amygdaloid neurons recorded in vitro. Neurosci 50:811-830.

Washburn MS, Moises HC (1992b) Muscarinic responses of rat basolateral amygdaloid neurons recorded in vitro. J Physiol (Lond) 449: $121-154$.

Whittemore SR, Seiger A (1987) The expression, localization and functional significance of $\beta$-nerve growth factor in the central nervous system. Brain Res Rev 12:439-464.

Will B, Hefti F (1985) Behavioural and neurochemical effects of chronic intraventricular injections of nerve growth factor in adult rats with fimbria lesions. Behav Brain Res 17:17-24.

Williams LR (1991) Exogenous nerve growth factor stimulates choline acetyltransferase activity in aging Fischer 344 male rats. Neurobiol Aging 12:39-46.

Williams LR, Rylett RJ (1990) Exogenous nerve growth factor increases the activity of high-affinity choline uptake and choline acetyltransferase in brain of Fisher 344 male rats. J Neurochem 55:1042-1049.

Williams LR, Varon S, Peterson GM, Wictorin K. Fischer W, Bjorklund A, Gage FH (1986) Continuous infusion of nerve growth factor prevents basal forebrain neuronal death after fimbria fornix transection. Proc Natl Acad Sci USA 83:9231-9235.

Williams LR, Vahlsing HL, Lindamood T, Varon S, Gage FH, Manthorpe $M$ (1987) A small-gauge cannula device for continuous in fusion of exogenous agents into the brain. Exp Neurol 95:743-754.

Williams LR, Jodelis KS, Donald MR (1989a) Axotomy-dependent stimulation of choline acetyltransferase activity by exogenous mousenerve growth factor in adult rat bsal forebrain. Brain Res 498:243256.

Williams LR, Jodelis KS, Donald MR, Yip HK (1989b) Exogenous nerve growth factor stimulates choline acetyltransferase activity in basal forebrain of axotomized and aged rats. New York: Plenum.

Williams LR, Rylett RJ, Ingram DK, Joseph JA, Moises HC, Tang AH, Mervis RF (1993) Nerve growth factor affects the cholinergic neurochemistry and behavior of aged rats. Prog Brain Res 98:251-256.

Womble MD, Moises HC (1992) Muscarinic inhibition of M-current and a potassium leak conductance in neurones of the rat basolateral amygdala. J Physiol (Lond) 457:93-114.

Womble MD, Moises HC (1993) Muscarinic modulation of conductances underlying the afterhyperpolarization in neurons of the rat basolateral amygdala. Brain Res 621:87-96.

Woolf NJ, Butcher LL (1982) Cholinergic projections to the basolateral amygdala: a combined Evans blue and acetylcholinesterase analysis. Brain Res Bull 8:751-763. 